\title{
Research Paper \\ Health Survey of Elderly Residents in Rural Areas of Ashtian City: Markazi Province, 2015
}

\author{
Hossein Hatami', Babak Eshrati², *Effat Kalateh ${ }^{1}$ \\ 1. Department of Public Health, School of Health, Shahid Beheshti University of Medical Sciences, Tehran, Iran. \\ 2. Department of Epidemiology, School of Health, Arak University of Medical Sciences, Arak, Iran.
}

Citat On: Hatami H, Eshrati B, Kalateh E. [Health survey of elderly residents in rural areas of Ashtian city: Markazi province, 2015 (Persian)]. Iranian Journal of Ageing. 2016; 11(2):250-257. http://dx.crossref.org/10.21859/sija-1102250

: http://dx.crossref.org/10.21859/sija-1102250

Received: 04 Mar. 2016 Accepted: 28 May 2016

Key words: Chronic diseases, Elderly, Health, Rural

\begin{abstract}
A B S T RACT
Objectives With the increasing life expectancy and aging density of population in some communities, the world's older population is rapidly increasing. With age, there is a gradual reduction in physical activities thereby leading to an increased prevalence of chronic diseases and reduced individual and social performance in elderly individuals. The importance of this present study can be noted from the factors including changing epidemiological pattern of disease in the elderly, susceptibility to the chronic diseases and increasing number of seniors facing relative health issues but deprived from healthcare needs. In order to optimize the management and careful planning of the healthcare services for the rural elderly, there is a need for extensive research in this field. The aim of this study was to evaluate the health status of elderly patients living in the rural cities of Ashtian city, Markazi Province.

Methods \& Materials This cross-sectional and descriptive-analytical study included 200 elderly people from Ashtian villages selected using the cluster sampling technique. After gaining consent from the participants, the required information was collected through questionnaire, physical examination, and laboratory tests. The results of the tests were processed using SPSS software. Chi-square test was also used, and $\mathrm{P}<0.05$ was considered to be significant.

Results This study consisted of 126 females and 74 males of which $156(78 \%)$ were illiterates, 52(26\%) were widows, $2(1 \%)$ were single, $32(16 \%)$ were living alone, and $10(5 \%)$ were smokers. The prevalence of disease noted in this study is given below: osteoarthritis, 163(81.5\%); static and dynamic imbalance, 138(69\%); hypertension, 120(60\%); hyperlipidemia, 111(55.5\%); urinary disorders, 99(49.5\%); depression, 95(47.5\%); cognitive disorders,92(46\%); hearing problems, 88(44\%); nutritional problems, 83(41.5\%); sleep disorders, 76(38\%); angina, 67(33.5\%); and diabetes, 18(9\%). Moreover, there was a significant relationship with widowhood $(P<0.027)$, illiterate $(P<0.001)$, living alone $(P<0.025)$ and sex $(\mathrm{P}<0.001)$

Conclusion The findings of this study suggested that physical diseases and functional limitations among elderly people in rural areas are a very crucial matter. Based on the results of this research and high frequency of chronic diseases in the rural elderly, especially osteoarthritis, imbalance, depression, hypertension, nutritional problems, vision and hearing problems- and angina diseases, the screening and monitoring activities for these diseases should be duly executed. The study also revealed that certain sections of the society including women, elderly, less educated, and unemployed, either living in celibacy or in the village are faced with several health problems. Thus, special attention should be paid to the vulnerable groups in terms of the health policies dedicated for their welfare.
\end{abstract}




\title{
بررسى وضعيت سلامت سالمندان در روستاهاى آشتيان: استان مركزى، سجوس
}

\author{
حسين حاتمى'، بابك عشرتى'، "عفت كلاته'

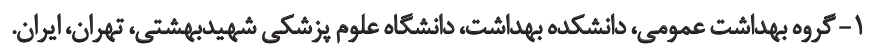

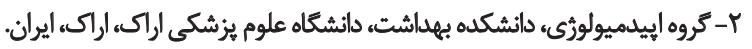

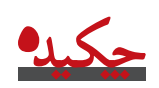

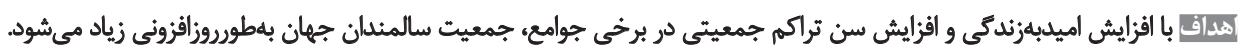

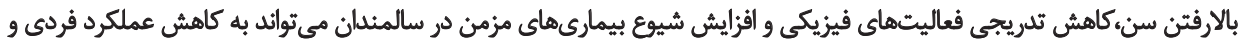

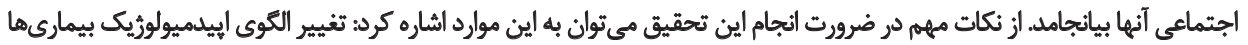

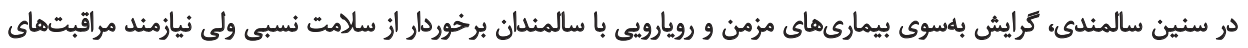

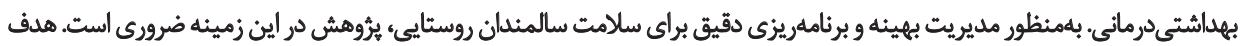

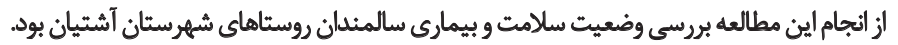

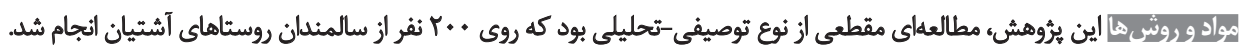

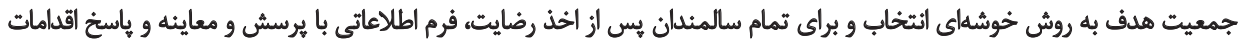

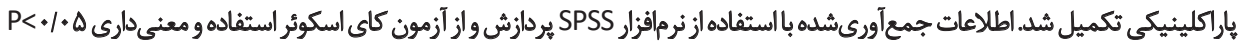

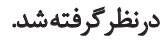

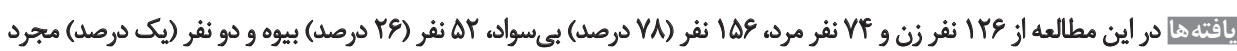

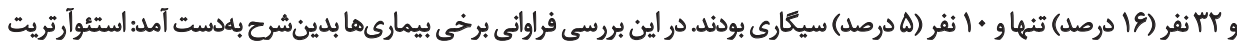

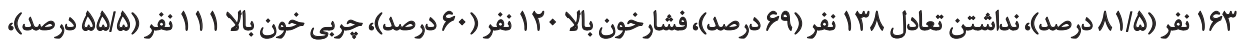

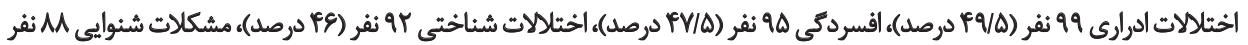

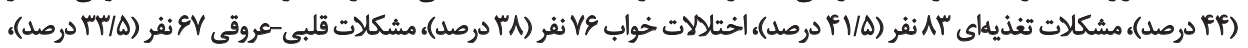

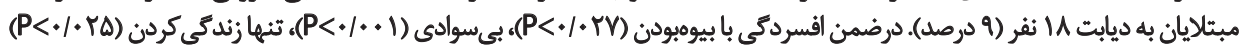

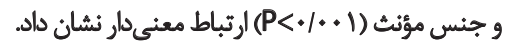

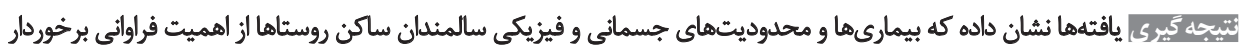

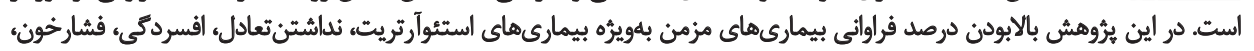

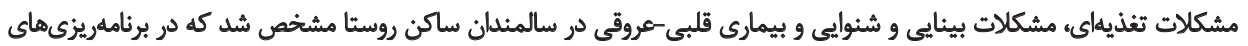

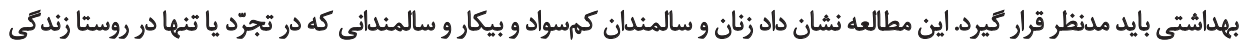

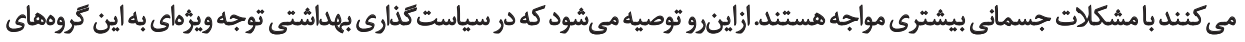$$
\text { خاص شودا }
$$

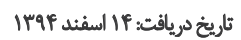

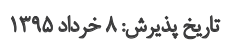

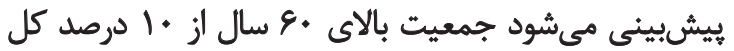

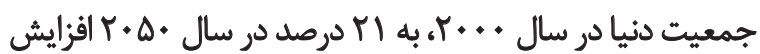

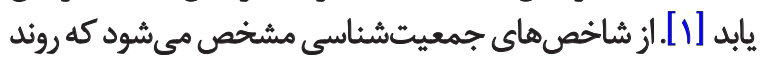

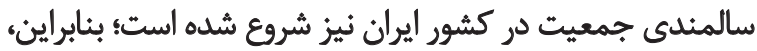

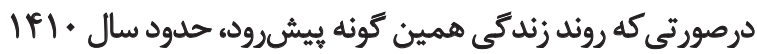

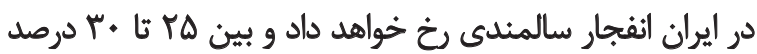

سالمندى يك روند زيست طبيعى و مرحله مهيمى از مراحل

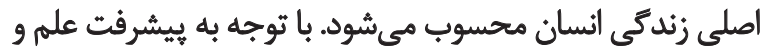

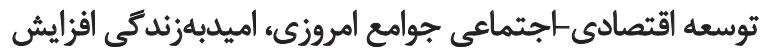

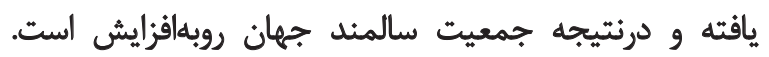

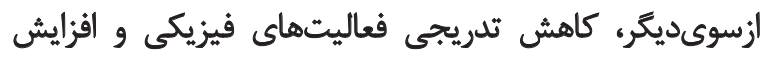

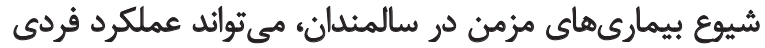

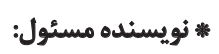

كتير عفت كلاته

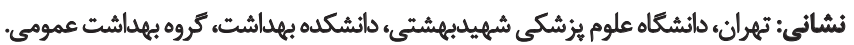

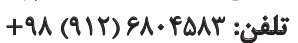
e.kalateh@gmail.com: بهت الكترونيكي: 
•افراد ديكرى نيز به بررسى شيوع بيمارىهاى مختلف و ارتباط

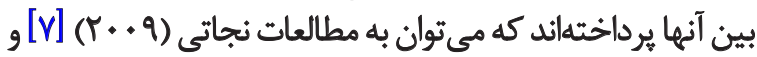

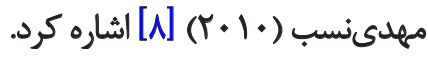

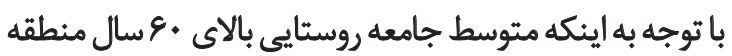

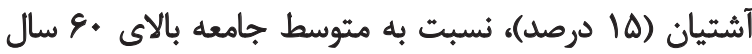

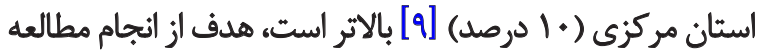

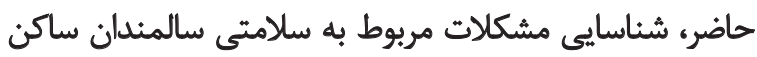
روستاهاى آشتيان درنظر مرفته شده است.

ورو مطالعه

يثروهش حاضر، ئروهشى مقطعى و از نوع توصيفى -تحليلى بود

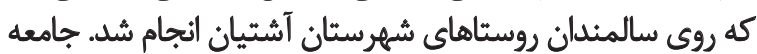

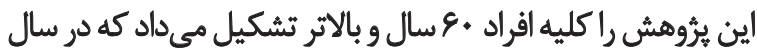

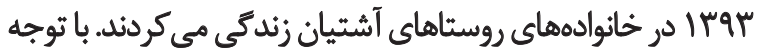

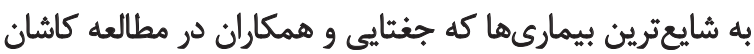

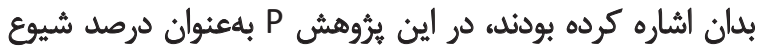

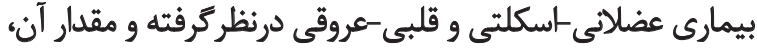

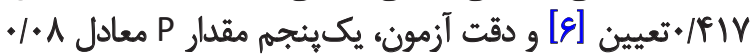

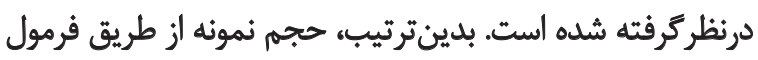

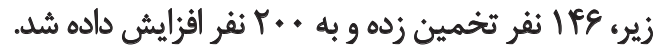

$$
n=\frac{n=Z_{1-\alpha / 2} \cdot P(1-P)}{d^{2}} \quad \begin{array}{ll}
P=\cdot / F \mid \gamma \\
d=\bullet / \cdot 1
\end{array}
$$

براى سهولت انجام مطالعه از نمونه ميرى خوشهاى استفاده و

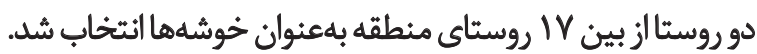

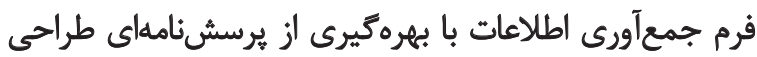

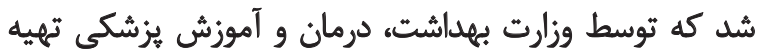

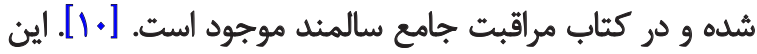

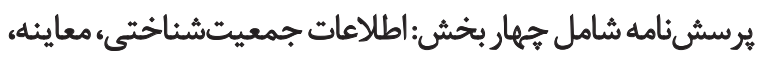
هرسش از سابقه بيمارى ها ونتايج ياراكلينيك بودي

ابتدا با مراجعه به خانههاى بهداشت روستاهاى خوشه، فهرست

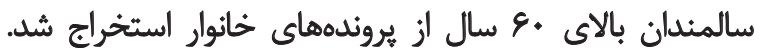

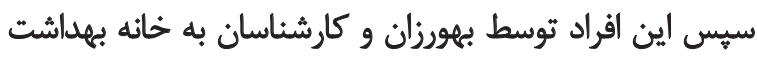

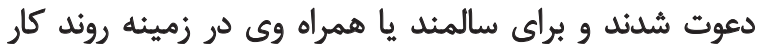

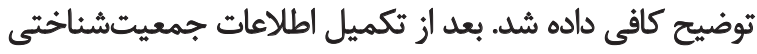

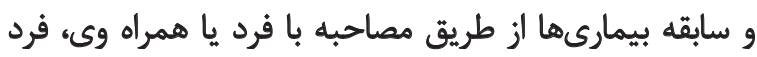

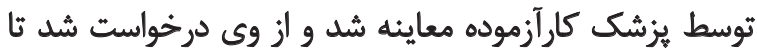
آزمايشهاى لازم را انجام دهد.

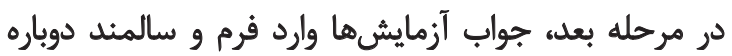

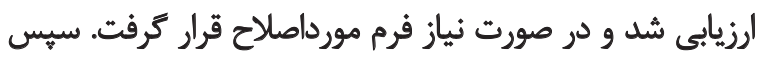

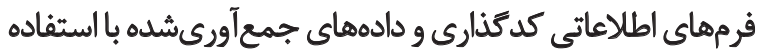
الز نسخه 18 نرمافزار SPSS تجزيهوتحليل شاريل شد. براى تعيين بادين
جمعيت در سنين بالاى •ه سال قرار خواهئد كرفت [Y]]. ازيكسو، تغيير الكوى همدگيرشناختى بيمارىها در سنين

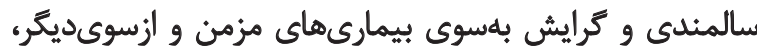

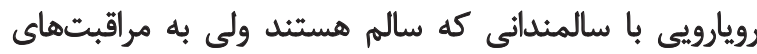

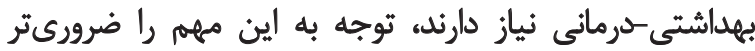

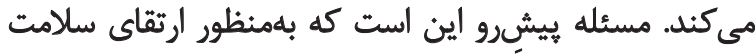

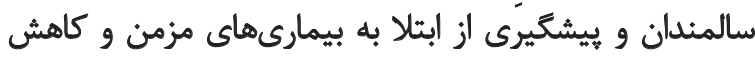

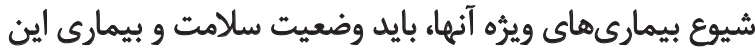

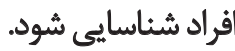

دركشور ما، مطالعات زيادى در حوزه سالمندى صورت نئكرفته

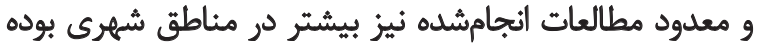

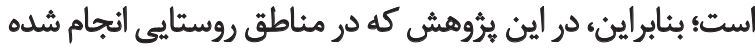

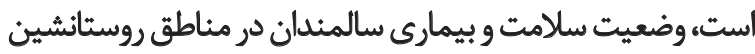

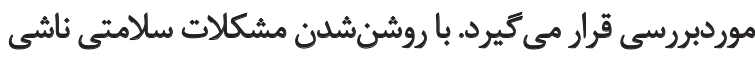

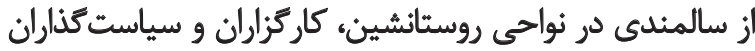

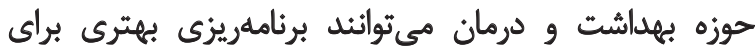
بيشكيرى و مديريت اين معضلات داشته باشئد.

اكرجه تاكنون مطالعات جامعى در سالمندان روستايى ايران

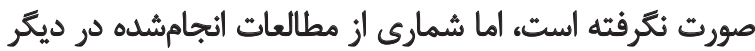
كروههاى اجتماعى بدينش المرح است:

•براساس مطالعات اليزا، ده بيمارى شايع در سالمندان آمريكا

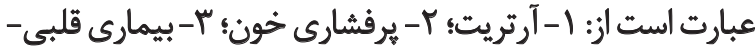

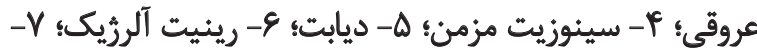

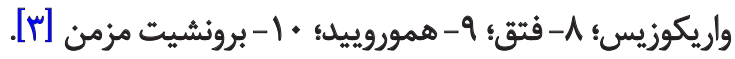

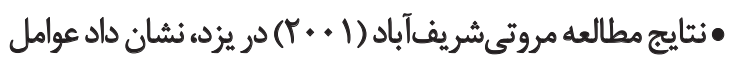

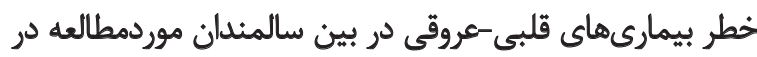

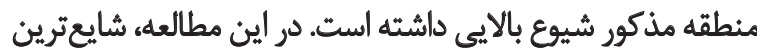

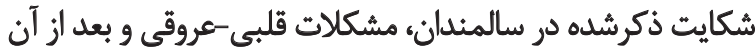

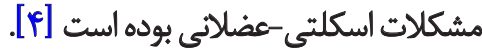

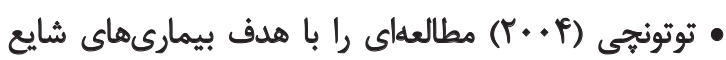

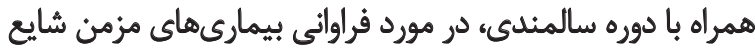

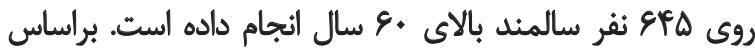

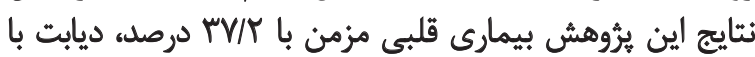

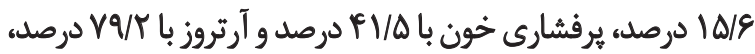

شايعترين بيمارى هاى دوران سالمندى شناخته شده است [هارئ.

• براساس ثروهش توصيفى مقطعى كه جغتايى و همكاران

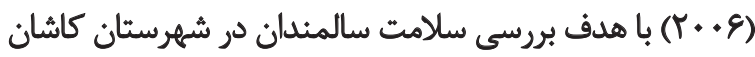

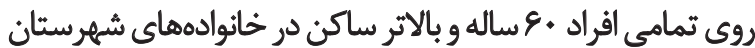

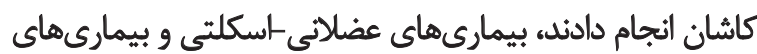

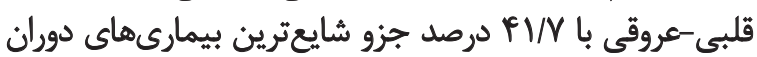

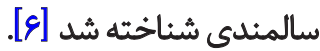


و مصرفكنيده الكل صفر درصد بود. در مطالعه حاضر، فراواثي بيمارىهاي استئوآرتريت بهاعا نفر

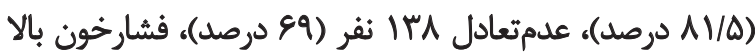

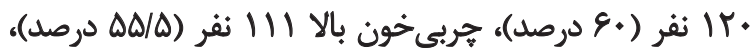

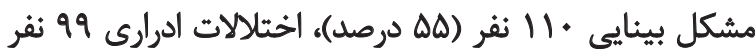
FV/Q

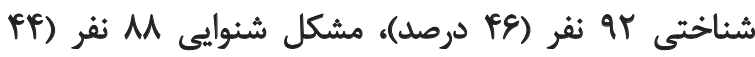

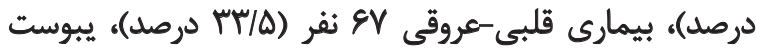

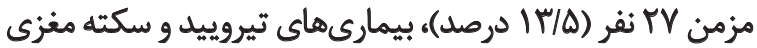

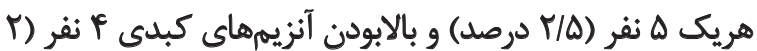

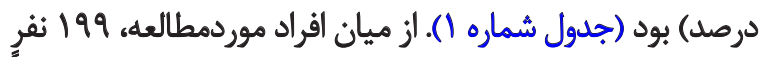

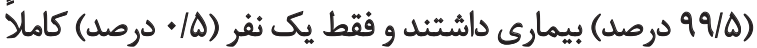

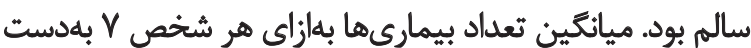

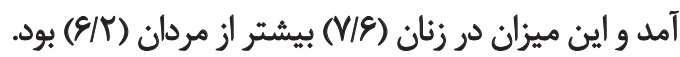
بين بيمارىهاى قلبى-عروقى و جنسيت ارتباط معنى ار

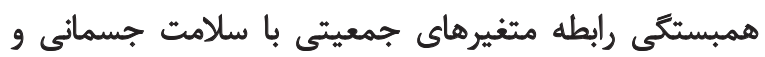

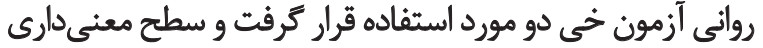

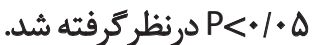

يافتهها

در اين يُروهش، •.r. نفر سالمند ساكن روستاهاى آشتيان

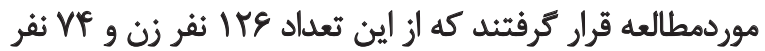

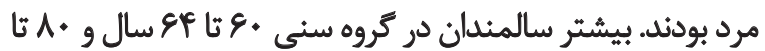

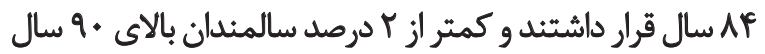

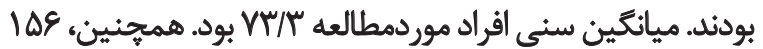

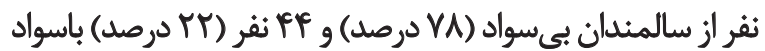

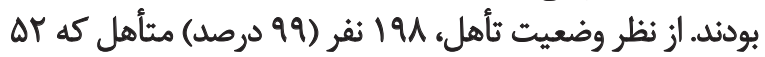

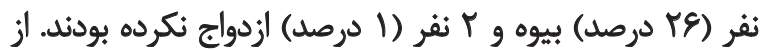

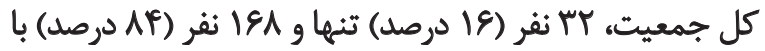

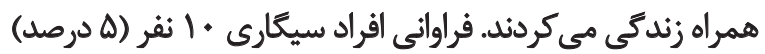

جدول ا. درصد شيوع بيمارىهاى مختلف.

\begin{tabular}{|c|c|c|c|c|c|}
\hline P-value (ارتباط جنس با ييماري) Pي & شيرع در مردان & شيوع دو زنان & شيوع & بيماريها & رديف \\
\hline.$/ P n$ & $\Delta \& / A$ & $81 / 9$ & q. & فشارخون بالا & 1 \\
\hline.$/ .4 \Delta$ & $m / m$ & HNG & $M / \Delta$ & بيمارى عروقى & r \\
\hline . /rrq & $\Delta /{ }^{\circ}$ & $1 . / m$ & ND & سكته قلبيى & $r$ \\
\hline . & - & $p$ & $r / \Delta$ & سكته مغزى & $\varphi$ \\
\hline . NET & $r \Delta / /$ & $P \Delta / T$ & $P V / Q$ & مشكل تغذيه & $\Delta$ \\
\hline ./ATY & $\Delta 1 / F$ & $\Delta V / I$ & $\Delta \Delta$ & مشكل بينايع & 8 \\
\hline$+|\mu|$ & FNE & $r \mid / \mu$ & $p f$ & مشكل شنوايى & $\checkmark$ \\
\hline$+1+\infty 1$ & $r / /$ & $\Delta V / I$ & $P V / \Delta$ & افسردتى & $\Lambda$ \\
\hline ./Mes & $M / A$ & $f+/ \Delta$ & ra & مشكل خواب & 9 \\
\hline . /Dpq & $R / T$ & ev/s & pe & اخدتالالات شُناختي & 1. \\
\hline.$/ 24 \Delta$ & ENG & 99 & 99 & ت & 11 \\
\hline . $p$ pis & $P \Delta / q$ & $\Delta \backslash / \varepsilon$ & $P q / \Delta$ & اختلالات ادرارى & ir \\
\hline$\cdot / r+$. & $9 / 0$ & $10 / 9$ & $16 / \Delta$ & ييوست & ir \\
\hline$+1+40$ & $v^{\prime} / r$ & $1 \otimes / V$ & $A V / \Delta$ & استئوآرتبريث & if \\
\hline$+1 \cdot n^{f}$ & $\mathrm{FV} / \mathrm{T}$ & $8 . / \pi$ & $\Delta \Delta / \Delta$ & جربى خون بالا & 10 \\
\hline . & $8 / 1$ & $1 . / \mu$ & 9 & ديابت & is \\
\hline ./T99** & • & $r / T$ & r & مشكل كبد & iv \\
\hline$\cdot / r \cdot r$ & . & f & $r / \Delta$ & تيروييد & $M$ \\
\hline
\end{tabular}


عدمتعادل، فشارخون بالا، جربى خُون بالا، مشكل بينايى،

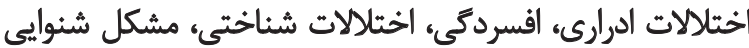

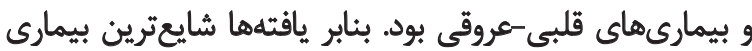

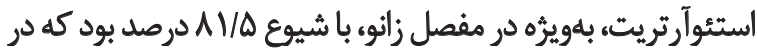

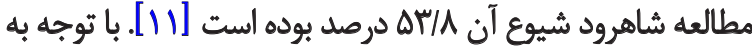

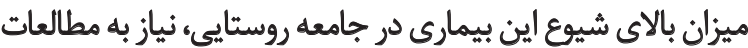

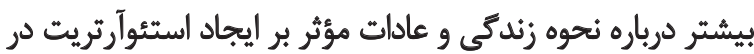

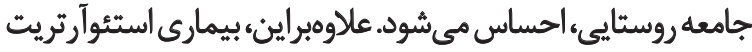

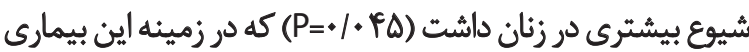
لازم است به سالمندان زن بيشتر توجه شود.

دومين بيمارى شايع در اين مطالعه، عدمثعادل در حالت ايستاو

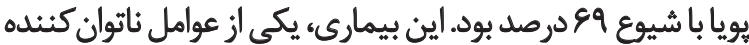

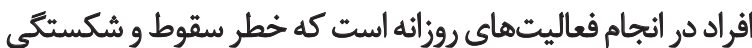

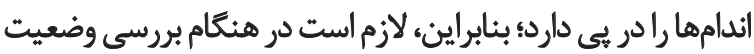

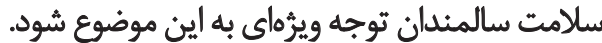

4.9.

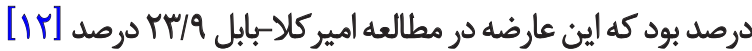

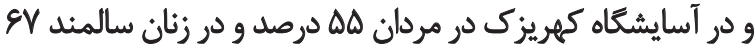

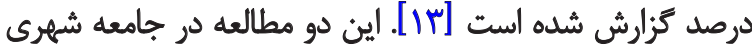

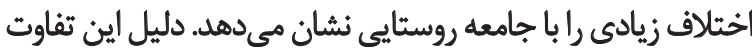

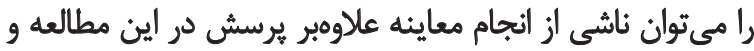

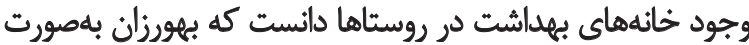

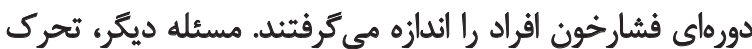

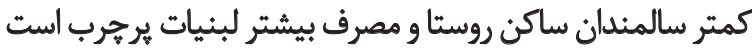
كه از علل زميئهساز فشارخون بالا محسوب مي مشود.

جهارمين بيمارى شايع در اين تحقيق، جربى خون بالا باشيوع

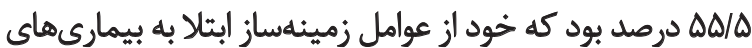

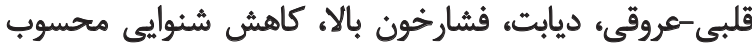

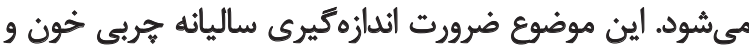
آموزش رزيم غذايى صحيح را روشن مى مسازد.

ينجمين بيمارى شايع در اين بررسي، مشكل بينايى با شيو

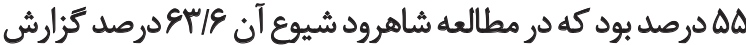

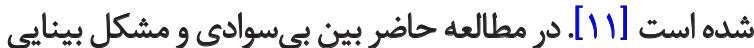

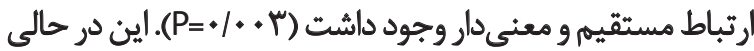

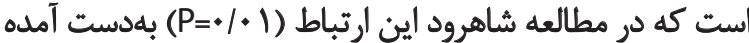

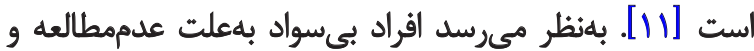

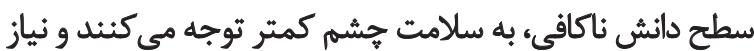
به آموزش و توجه بيشترى دارند.

ششمين بيمارى شايع در اين ثروهش، اختلالات ادرارى با

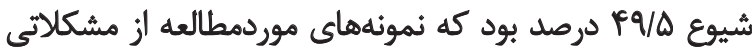

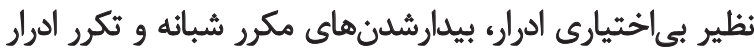

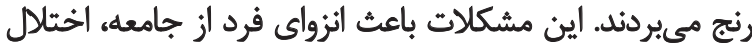

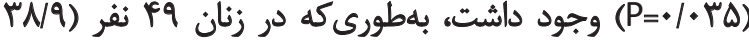

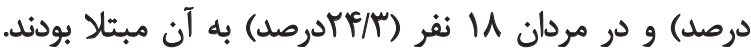

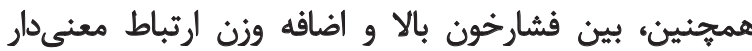

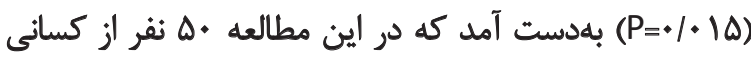

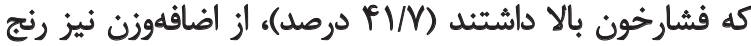

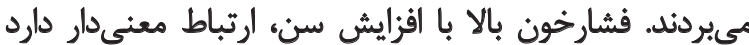
. $(P<+1 \bullet+1)$

در بررسى آزمايش كامل ادرار، بr نفر (ع أدرصد) بروتئينورى باري

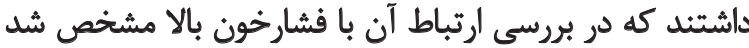

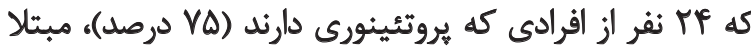

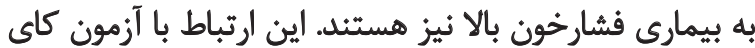

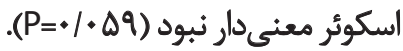

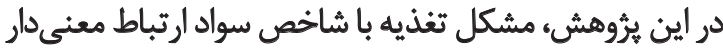

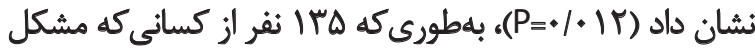

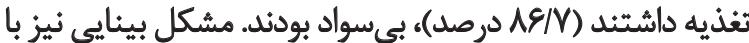

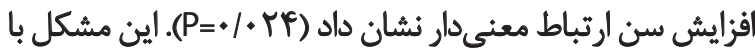

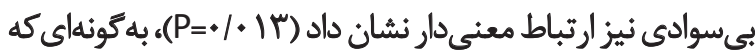

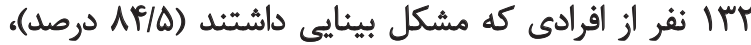

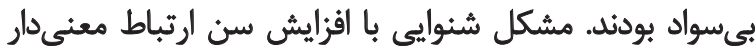

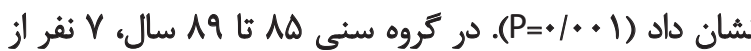

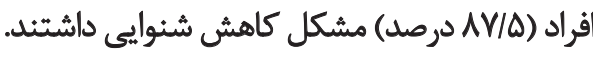

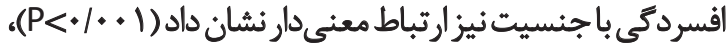

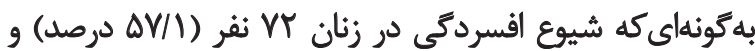

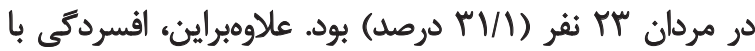

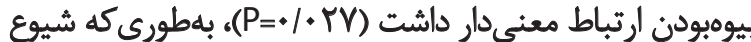

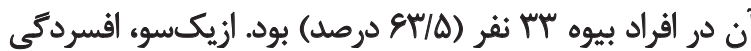

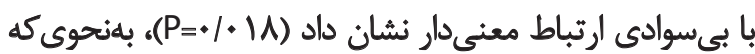

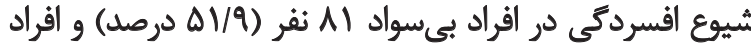

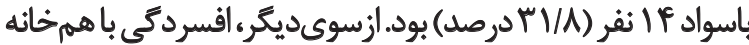
نداشتن ارتباط معنى دار داشت (PA

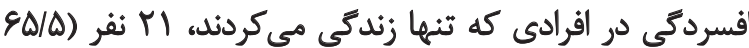

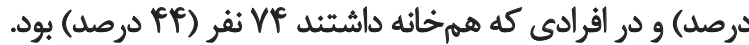
عدمتعادل با افزايش سن، ارتباط مستقيم و معنى دار نشان داد

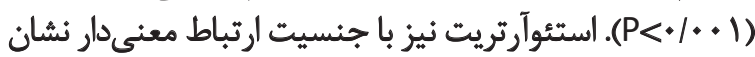

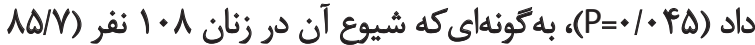

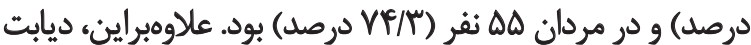

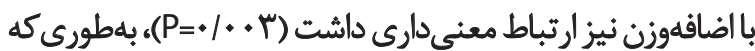

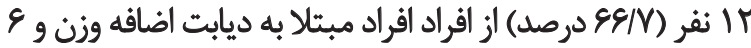

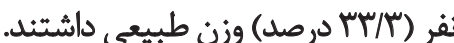
بحثث در اين مطالعه شايعترين بيمارىها بهترتيب: استئوآرتريت. 
سالمند آينده، افزايش قابل توجه خواهد داشت.

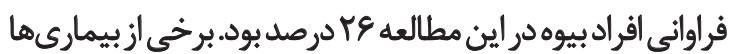

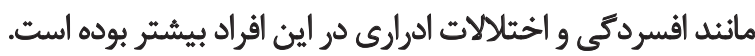

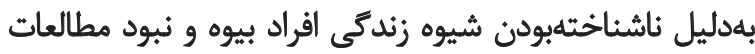

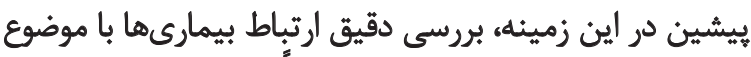

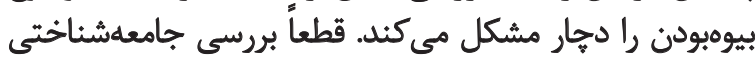

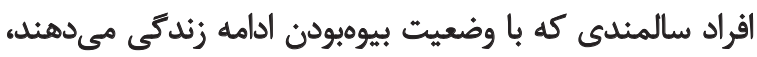
مى تواند به روشنشدن اين موضوع كمك كند.

\section{نتيجه ئيرىنهايى}

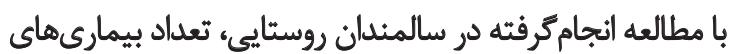

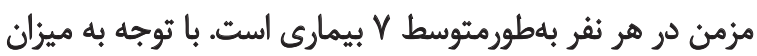

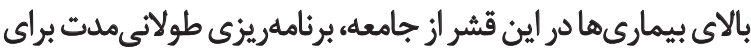

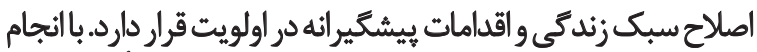

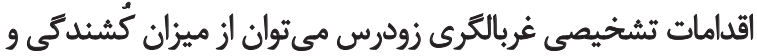

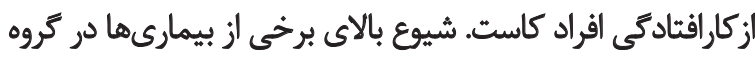

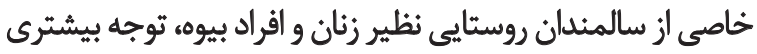

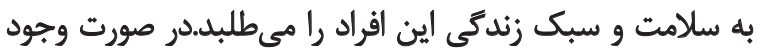

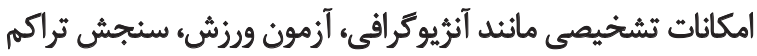

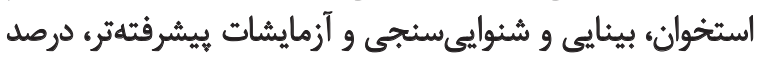
شيوع بيمارىها با دقت بيشترى قابل باستخراج بود.

محدوديتها

يكى از محدوديتهاي اين تحقيق، مربوط به افرادى بود كه

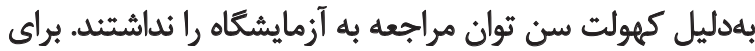

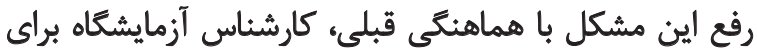

نمونه كيرى به محل خانه بهداشت روستايى مراجعه مى كردا.

يشينهانها

ميشينهاد مى شود يُروهشى كسترده در سطح ملى براي تعيين

مشكلات موجود در سلامت سالمندان روستاييى انجام كيرد.

$$
\text { تشكر وقدرواني }
$$

اين مقاله بركرفته از بايانانامه دوره عالى بهداشت عمومى

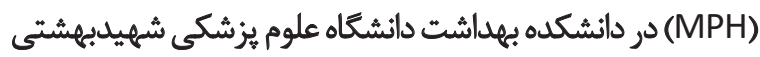

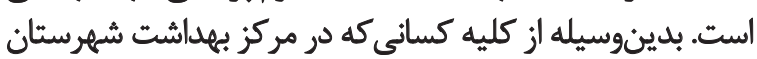

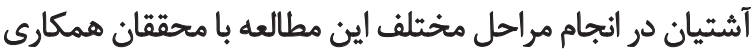
كردهاند، تقدير و تشكر مى شيود.
در خواب، مصرف كمتر آب و بهدئبال آن عفونت ادرارى و آسيبديدكى كليهها مى شودود.

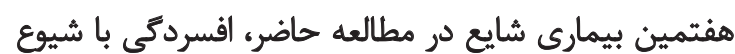

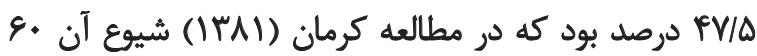

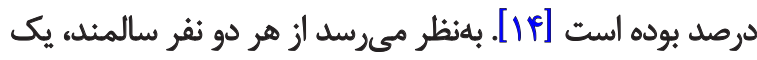

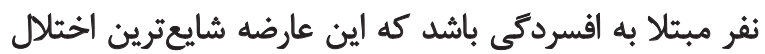

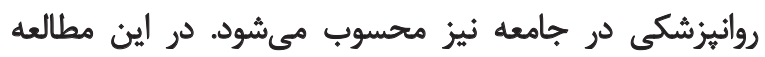

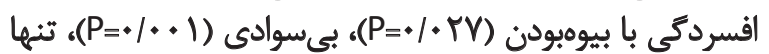

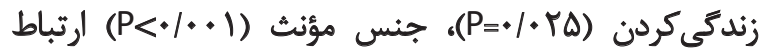

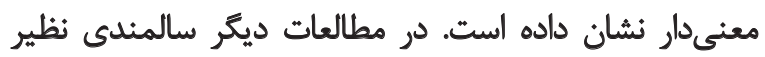

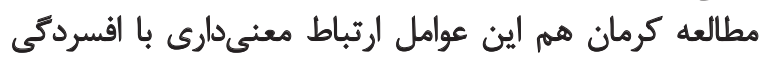

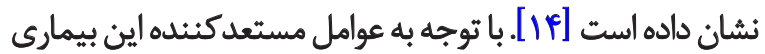

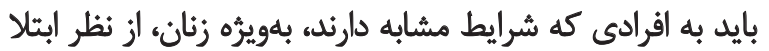

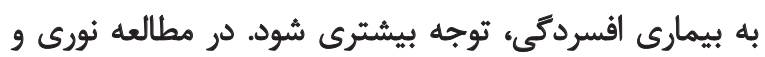

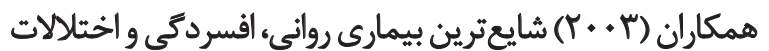

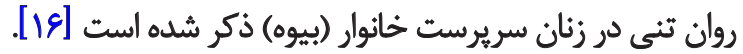
در اين مطالعه شيوع اختلالات شناختيى ع\& ألات درصد بود.

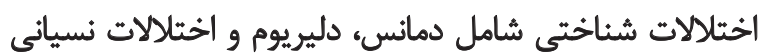

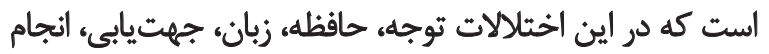

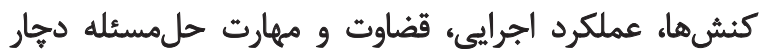

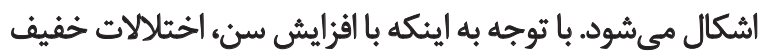

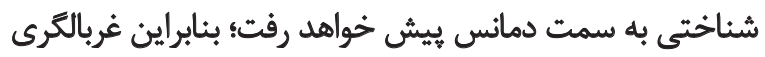

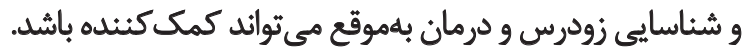

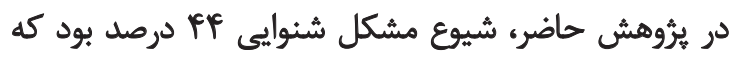

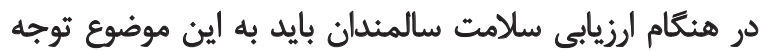

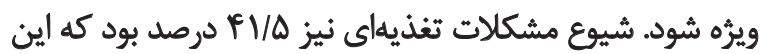

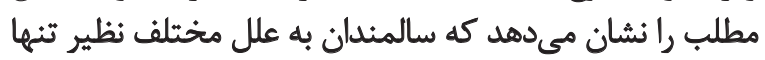

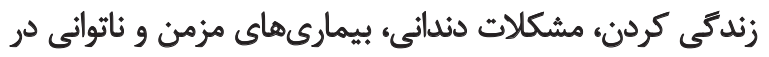

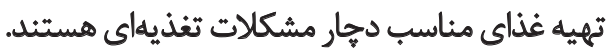

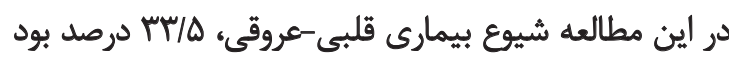

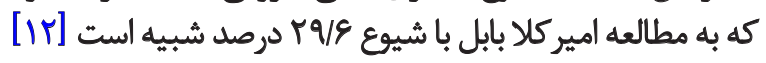

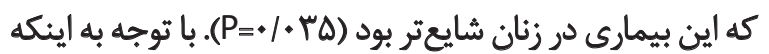

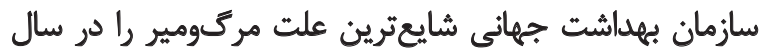

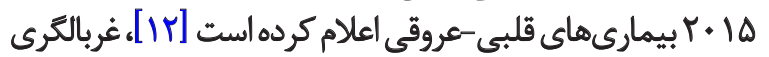

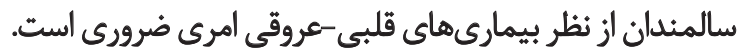

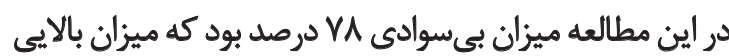

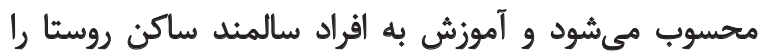

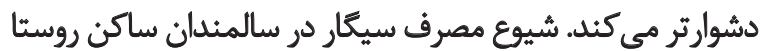

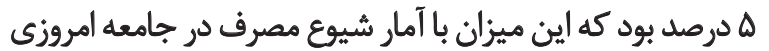

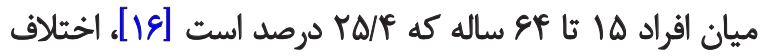

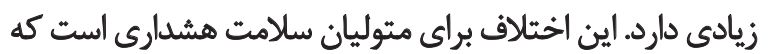

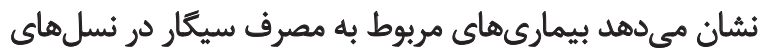




\section{References}

[1] World Health Organization. Ageing and health program: ageing, exploding the myth. Geneva: World Health Organization; 1999.

[2] Mirzai M, Shams M. [Demography of aged people in Iran based on censuses of population from 1325-1385 (Persian)]. Iranian Journal of Ageing. 2007; 2(3):326-31

[3] Ghezzi EM, Ship JA. Systemic diseases and their treatments in the elderly: impact on oral health. Journal of Public Health Dentistry. 2000; 60(4):289-96

[4] Morovati Sharifabad MA, Hosseini Sharifabad M. [Activities of daily living status (ADL) among elderly in the Yazd district (Persian)]. Journal of Shahid Sadoughi University of Medical Sciences \& Health Services. 2001; 8(4):46-53.

[5] Toutounchi P. [Chronic diseases and senile changes in the elderly population, Tehran, Iran (Persian)]. Journal of the Iranian Institute for Health Sciences Research. 2004; 3(3):219-25.

[6] Joghatayi MT, Nejati V. [Health status of elderly people in Kashan city (Persian)]. Iranian Journal of Ageing. 2006; 1(1):3-10.

[7] Nejati V. [Assessing the health status of elderly people in the province of Qom, 2007 (Persian)]. Journal of Qazvin University of Medical Sciences. 2009; 13(1):67-72.

[8] Mehdinasab S, Haddad poor AA, Sarrafan N, Dashtbozorg A, Ebrahimi M. Prevalence and Evaluation of risk factors in primary Knee Osteoarthritis. Jundishapur Scientific Medical Journal. 2010; 9(2):135-41.

[9] Ma'sumi Sh. [Statistical yearbook of the Markazi province (Persian)]. Arak: Ministry of Markazi Province Publication; 2013.

[10] Khoshbin S, Radpooyan L, Azizabadi Farahani A. [Training manual on integrated care for older people, especially doctors (Persian)]. Tehran: Tandis Publications; 2010

[11] Sadeghiyan F, Raei M, Hashemi M. [Elderly and health problems: a cross sectional study in the Shahroud township (Persian)]. Iranian Journal of Ageing. 2011; 6(2):26-30.

[12] Hosseini SR, Zabihi A, Savadkohi S. [Prevalence of chronic diseases in elderly population in Amirkola (2006-2007) (Persian)]. Journal of Babol University of Medical Sciences. 2008; 10(2):68-75.

[13] Sharifi F, Mirarefin M, Fakhrzadeh H. [Prevalence of hypertension and diabetes in elderly residents of Kahrizak (Persian)]. Iranian Journal of Ageing. 2009; 4(1):16-29.

[14] Rajabizadeh G, Ramazani A. [Prevalence of depression in Kermanian Geriatrics, 2002 (Persian)]. Journal of Rafsanjan University of Medical Sciences. 2004; 3(1):58-66.

[15] Ebadi M, Vahdaninia M, Azin A. [Prevalence of tobacco consumption: Iranian health perception survey (Persian)]. Hakim Research Journal. 2011; 10(3):365-72.

[16] Nouri M, Minakari M, Sadrosadat SJ, Shahidi S, Heidari M. [Investigating of the psychological health of women heads of household (Persian)]. Journal of Rehabilitation. 2003; 4(2):37-44. 
